\title{
Visual Image of Architectural Elements as the Identity of Menanga Traditional Village
}

\author{
Agus S Sadana $^{1^{*}}$, Ashri Prawesthi $\mathrm{D}^{2}$, Adryanto Ibnu Wibisono ${ }^{3}$ \\ 1,2,3 Department of Architecture, Pancasila University, Jakarta, Indonesia. \\ *Corresponding author. Email: agussadana@gmail.com
}

\begin{abstract}
The Menanga Village has interesting traditional houses and village layout. There are some unique architectural shapes, easily known and remembered by the observers' minds. This study combines descriptive and graphical method with quantitative analysis to translate the mental map into a variable map, in order to determine the role of architectural elements as a place identity in village space. Based on the mind map, the Lynch five elements in Menanga Village are distributed into four sequences as district and path, edges, nodes, and landmarks. The results of the study show that the district and path elements were remembered by all of the observers, edges were remembered by most observers, while nodes and landmarks were only remembered by a small number of them. The most dominant placemark element is the combination of traditional houses rows with the main corridors forming unique village visual character. The large river flow behind the residential area and the highway in the front of the village has an important role as a boundary line of the village's core. Other physical elements that are supposed functioned as nodes and landmark markers are too weak and unable to be a place marker or as a navigation tool for people who want to go elsewhere in the village core. Therefore, structuring and façade repairing of architectural elements are needed to realize the visual linkage among the elements. It aims to lift the image and identity of Menanga as a traditional architectural village that needs to be preserved.
\end{abstract}

Keywords: Visual image, identity, preservation, traditional village

\section{INTRODUCTION}

Menanga Village, located in Semendawai Barat, Ogan Komering Ulu Timur, South Sumatra, has unique architectural forms. The combination of unique shapes and interesting spatial characteristics is a situation that's easily remembered for a long time in the observer's minds. Lack of maintenance and physical arrangement causes a reduction in the architectural appearance of Menanga Village. Therefore, research is needed to explore the local potential that can be developed to revitalize Menanga's identity as a traditional village that's worth preserving.

The strengths of the architectural elements of Menanga Village are then summarized into a variable map developed from a mental map. Lynch [1] describes the image of the place as a reciprocal process between the observer and the observed objects, as a result of an observer's perception of the environment.

\section{LITERATURE REVIEW AND RESEARCH OBJECT STUDY}

\subsection{Image of Place and Observers' Mental Map}

The image of a place is related to a person's memory of a place with the elements of a place marker stored in the observer's memory as a mental image known as mental maps. A mental image is a schema built to visualize and assimilate information that is also known as cognitive maps [2], which are imagined in sketch drawings.

In the architectural environment, spatial cognition has a basic concept of imageability and legibility. Imageability is the quality of physical objects in generating a strong image for every observer. Legibility is a condition of how the observers easily navigate and move somewhere in an area with a guide to the physical elements [1,3]. Referring to Lynch elements [1], a mental map is an image that represents how people shape their perception, understand, and perceive their surroundings. The elements of the mental map include (1) landmarks, (2) paths, (3) nodes, (4) edges, and (5) districts. According to the generation type of assumptions, we divided the existed work into two categories. 


\subsection{Visual Identity of Architectural and Spatial Elements in Menanga Village}

The Menanga traditional village is a settlement that was built linearly with the Komering river flow. Menanga Village has the main pedestrian lane in the village core walled by the row of traditional houses [4]. The traditional Menanga house is called Rumah Ulu [5], which has a unique architectural form that attracts people to see, observe, and remember.

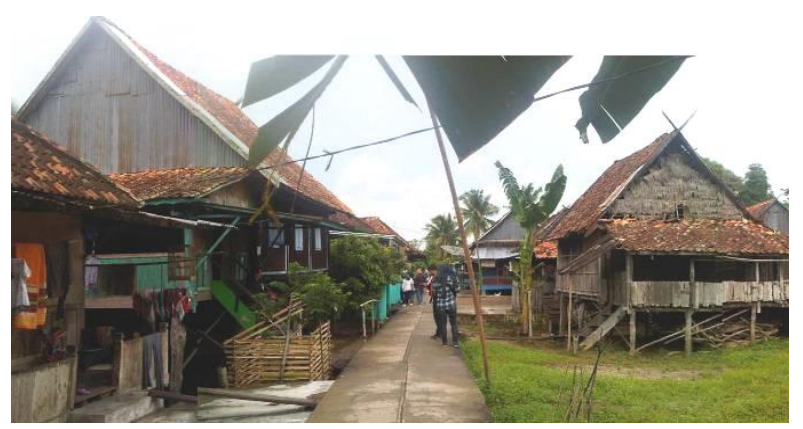

Figure 1 Main corridor and row of settlements in Menanga Village.

Visual quality is something that is produced by a vivid, complete picture, and unity [6]. Therefore, the visual quality captured by the observers is an important factor of the regional order, because it is built from a series of observers' perceptions by the different characteristics of the objects they see. Regarding the identity of the place, Lynch [1] describes that identity is formed by the quality of the physical environment, which can be understood through visual images interpreted by observers. It means that the concept of place identity refers to the relationship between the identity itself and the meaning felt by the people.

\section{METHOD, RESULTS, AND DISCUSSION}

This study combines three analysis methods, namely: descriptive method, graphical method, and quantitative analysis, to combine a lot of mental maps into a variable map. It aims to determine the role of architectural elements as a place identity in village space. Referring to the Purwanto and Darmawan work steps [3] to over-lay, the sketch graphic data was made by the respondents. Mental map sketches were collected from respondents of Architecture students who were conducting field studies at the research location. The information presented in the map sketch was combined quantitatively into a tabular form for analysis.

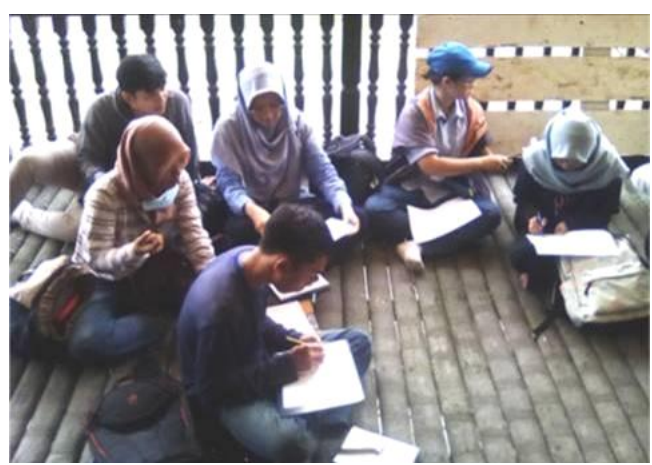

Figure 2 Process of moving a mental map into paper media.

\subsection{Research Findings}

Data collected is the result of recalling respondents' memories of the physical elements of placemark in the traditional settlement of Menanga. Referring to Lynch's concept [1], it can be seen that Menanga Village has all the elements. The five Lynch elements [1] are recognized by all observers at various levels. The distribution patterns of the elements identified by the observers are (1) districts and paths, (2) edges, (3) nodes, and (4) landmarks, as seen in Table 1.

Table 1 Gradation of architectural elements in Menanga

\begin{tabular}{|c|c|c|c|c|c|c|}
\hline \multirow{2}{*}{ Rank } & \multicolumn{2}{|c|}{ Element Status } & \multirow{2}{*}{\multicolumn{2}{|c|}{$\begin{array}{c}\text { Degree of } \\
\text { Marked } \\
(\%)\end{array}$}} & \multirow[b]{2}{*}{ Name/ Type of Objects } & \multirow[b]{2}{*}{$\begin{array}{l}\text { Group of } \\
\text { Elements }\end{array}$} \\
\hline & $\begin{array}{c}\text { Element } \\
\text { status }\end{array}$ & Sub status & & & & \\
\hline \multirow{3}{*}{1} & \multirow{3}{*}{ Dominant } & Dominant & \multirow{3}{*}{100} & 100 & $\begin{array}{c}\text { Row of } \\
\text { settlements }\end{array}$ & District \\
\hline & & Dominant & & 100 & Main corridor; Secondary corr. & Path \\
\hline & & Dominant & & 100 & Road & as Path \\
\hline \multirow{3}{*}{2} & \multirow{3}{*}{ Dominant } & Dominant & \multirow{3}{*}{100} & 100 & Road & as Edges \\
\hline & & Dominant & & 100 & River flow & Edges \\
\hline & & Not dominant & & 25 & Plantation/ forest & Edges \\
\hline 3 & \multicolumn{2}{|c|}{ Weak } & \multicolumn{2}{|c|}{34} & $\begin{array}{l}\text { Tomb; Mosque/ Prayer rooms; Hall; Toilet; School; Green Open Space/ Green Field; } \\
\text { Sports field }\end{array}$ & Nodes \\
\hline 4 & \multicolumn{2}{|c|}{ Very weak } & & 20 & $\begin{array}{c}\text { Nice/trad house; Bridge; Village Head/Village Office /Government Building; Secretary } \\
\text { House; Shop; Midwife; Sculpture; Gate }\end{array}$ & Landmark \\
\hline
\end{tabular}




\subsection{Physical Elements as Identity of Menanga Village}

District and path were observed by all respondents. It can be said that district and path are the most dominant elements, fastest to see and remember, and best mapped by observers. Edges were observed by $75 \%$ of respondents. It means that edges are quite dominant and easily known, but its form is not as clear as the two previous elements. Nodes and landmarks are the almost not found elements by respondents. It means that their existence as a placemark in the village's core space is too weak. Nodes are only known by $34 \%$ of respondents, while landmarks are only known by $20 \%$ of respondents. The distribution pattern of the placemark elements in Menanga Village is summarized into a variable map, as shown in Figure 3.

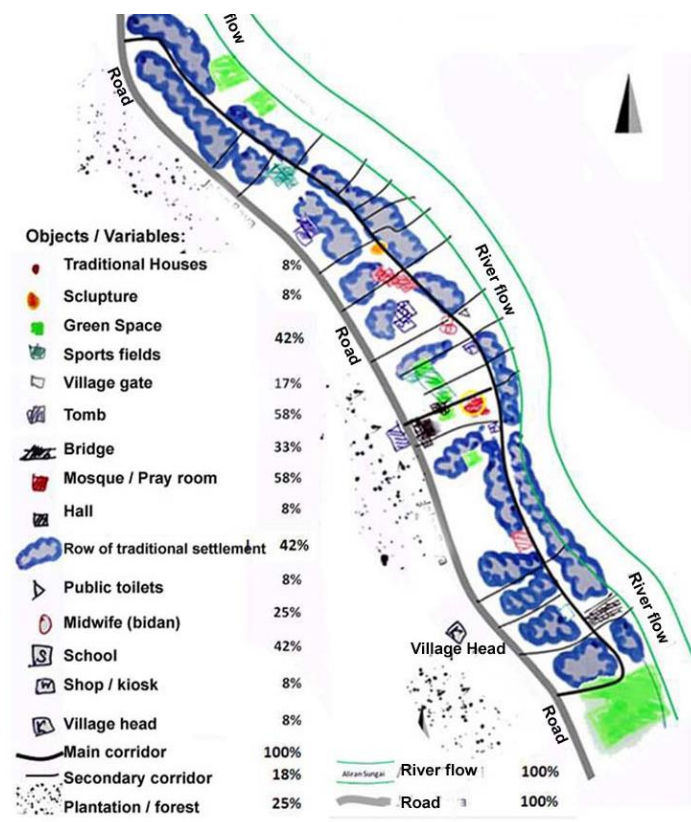

Figure 3 Menanga map of the variable.

Paths and edges can be remembered by all respondents; However, not all units were drawn in detail. The results of comparing the number of units in the sketch to the units in Google maps show that only a few secondary corridors and settlements units were drawn by respondents. However, the sketch of the mental map they made showed that the distribution patterns of these units filled the core of village space. The small number of units drawn by respondents can be understood because there are a vast number of existing units, so the observer's mind tends to remember these elements globally.

Edge elements are represented by three types of objects: roads, river flow, and plantation/forests. The road and river flow were easily recognized by observers, and each object was observed by $100 \%$. Another edge element is the plantation or forest. Their role as the boundaries of the village core is less well known by respondents, and it was only drawn by $25 \%$ of observers. It means that plantation or forest is the element that cannot be felt as village boundaries. The average combination of roads, rivers, and plantation/forests as village edges observed is $75 \%$.

In the research location, few residents or visitors are passing by, so that the observer cannot find the nodes as a point where people meet each other in the open space. Therefore, the performance of the node elements is only measured by the number of objects that function as a place for people to gather. The result is that the node was only observed at $34 \%$. These objects are tombs, mosques and prayer rooms, sports fields, green space or open land, and several other public facilities that are not parts of the main corridor environment.

Nodes are the space where people meet and gather with other people. The small numbers of people who are passing by and gathering in the public space cause the absence of nodes around the main corridor. Visual data search shows that there are a few unplanned gathering places. One of them is part of the house courtyard that is right next to the main corridor. It is an open area with a wooden bench where the children like to play.

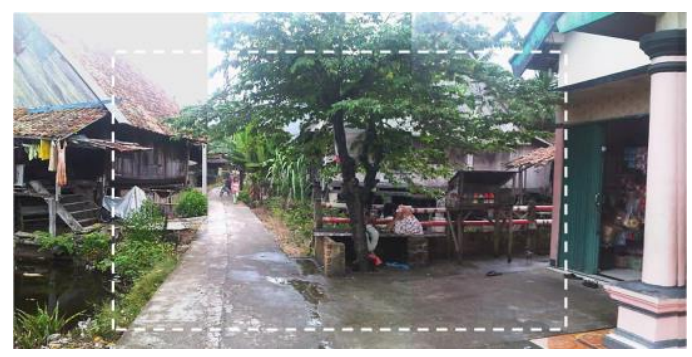

Figure 4 Sample of unplanned nodes.

Landmark is a vital placemark that can be represented by various elements standing out and easily visible from a distance. Based on mental map sketches, it is known by only a few of the respondents felt landmarks. It might be due to the elements that supposed to act the landmark hidden by the unorganized plot of village spaces. The results show that the landmark elements were only observed at $20 \%$.

There is a monument that can function as a landmark. The combination of mass form and its location in the t-junction of the village entrance corridor and the main corridor supposed to make it a clear landmark. Unfortunately, the monument covered with trees, so it would not be perceived by observers.

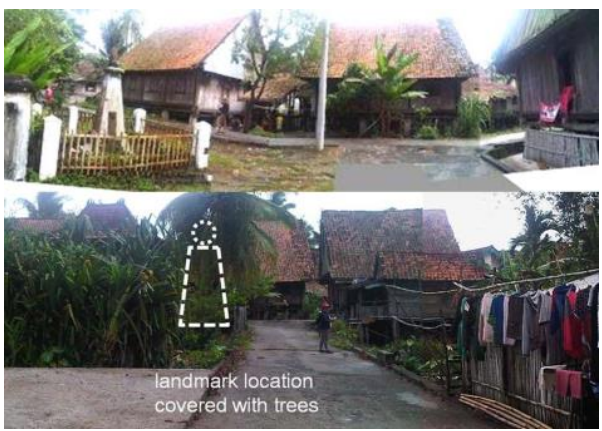

Figure 5 A monument as landmark obscured by trees. 
A kind of another object which is not an architectural element, but is quite scattered and easily seen along the village corridor are the mounds of firewood under the front of the house. The objects are easily seen by people, but they are not stored in the observers' minds. Maybe it is caused the objects is not an architectural object. A better layout and ordering these objects will be an effective placemark.

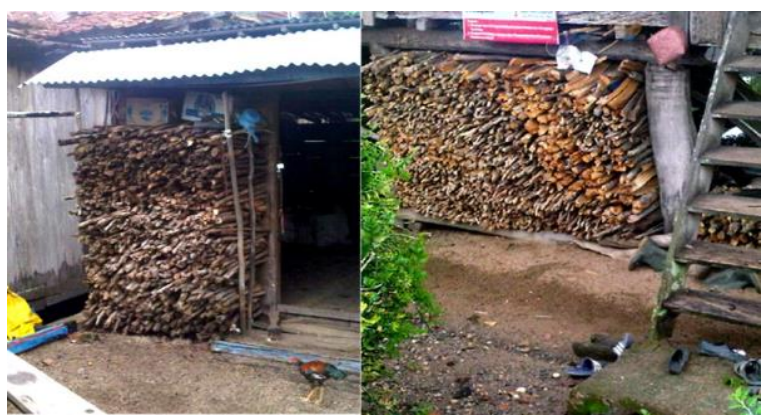

Figure 6 Mounds of firewood and potential as placemarks.

Lacking the role of the placemark elements in Menanga Village seems to be caused by poor visual linkage flow. That is a result of the presence of many new houses in the village core area. Meanwhile, to preserve the identity, there is a need for 'place legibility' in the village core area, which is the people's ease in understanding the layout of Menanga Village. The improvement of traditional houses façade within their surrounding infrastructure forms and reordering of visual linkage flow is expected to increase the role of placemark elements in Menanga Village. The concepts proposed can be seen in Figure 7.

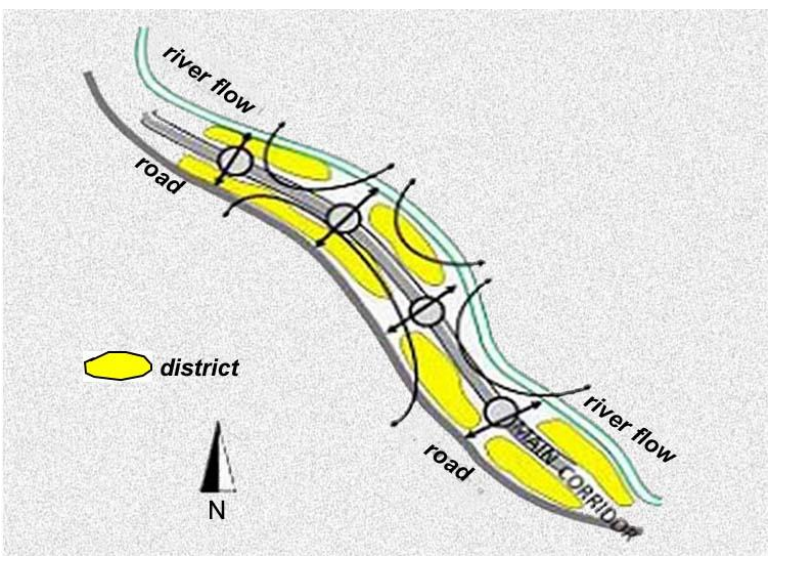

Figure 7 Visual linkage concept for Menanga Village.

\section{CONCLUSION}

This study found about 20 architectural objects that can be remembered and illustrated in sketches divided into five elements of the placemark. The role of each element varies. There are dominant elements and very weak elements as a placemark. The variations of the five elements roles are divided into four degrees: (1) district, and path in the first; (2) edges at the second, (3) nodes at the third, and (4) landmarks as the last degree. Lacking the role of some elements as a placemark causes the architectural identity of the Menanga Village to be less perceived by observers. The conclusion can be specified as follows:

- District and path are the most dominant elements and are formed by a row of traditional houses combined with the main village corridor.

- Edges as area boundaries are formed by road and river flow, and there is little influence from the surrounding plantation or forests.

- Nodes are not well known because there are not many people passing by and meet each other in the village corridor area so that there are no points found as places for people meeting and gathering in outdoor spaces. Nodes are represented by objects which are functioned as residential facilities.

- Landmarks are hard to find. They are marked by a few physical objects with less prominent visualization, so they cannot be a place marker for people in the distance.

Based on physical conditions, visual situations, and local potential in Menanga, it needs a concept of architectural order on visual linkage aspects to strengthen the visual connections between architectural and non-architectural objects, as well as non-physical elements in the village core area. The goal of it is that the elements can protect the identity of Menanga as a village with traditional architecture.

\section{ACKNOWLEDGMENT}

Data displayed in this paper were collected from mental map sketches drawn by the observers in January 2019. The observers were a small group of architecture students who took a field observation in Menanga Village.

\section{REFERENCES}

[1] K. Lynch, The Image of the City. Cambridge: The M.I.T. Press, 1960.

[2] Bonnici, and J. McGee. Cognitive map, Wiley Encyclopedia of Management, John Wiley \& Sons, 2014.

[3] E. Purwanto, and E. Dharmawan, Understanding image of the city based on spatial cognition of the observers case study: center of Semarang city, Tata Loka, vol. 15, no. 4 (2013) 248-261.

[4] A. S. Sadana, A. Prawesthi D, and A. Ibnu W, Visual image of place mark elements as local architectural identity in Menanga Village, Unpublished 
research report, Program Studi Arsitektur Universitas Pancasila, 2019. (translation)

[5] C. Murod, Traditional style architecture of Minanga area in Ogan Komering Ulu Regency, Research report, Program Studi Teknik Arsitektur Jurusan Teknik Sipil Fakultas Teknik Universitas Sriwijaya, 2002.

(translation)

[6] R.C. Smardon, J. F. Palmer, and J. Barone,

Foundation for Visual Researc Project Analysis, New

York: John Willey \& Sons, 1986. 